\title{
ESTUDIO DE BACTERIAS ASOCIADAS A ORQUÍDEAS (ORCHIDACEAE)
}

\author{
Emilia Ramos Zambrano ${ }^{1}$, Teresita Jiménez Salgado ${ }^{2,3}$ \& Armando Tapia Hernández ${ }^{2}$ \\ ${ }^{1}$ Escuela de Biologia. Universidad Autónoma de Puebla, México \\ ${ }^{2}$ Universidad Autónoma de Puebla, Laboratorio de Microbiología del suelo CICM. Edificio 76 Complejo de \\ Ciencias. 3er. Piso ciudad universitaria C. P. 72510. Puebla, México \\ ${ }^{3}$ Autor para correspondencia: terjimen@siu.buap.mx
}

México cuenta con 1106 especies y subespecies de orquídeas distribuidas en 159 géneros, de las cuales 444 especies y subespecies son endémicas representando el $40 \%$ de los taxas registrados en el país. Esta diversidad constituye un enorme potencial ornamental, que hasta la fecha no se ha aprovechado en toda su magnitud por los mexicanos, especialmente por sectores de la sociedad que cuentan con estos recursos fitogenéticos (Red de ornamentales 2004, Soto 1996)

Las orquídeas representan la cúspide de procesos evolutivos y ecológicos dentro del reino de las plantas, ya que han desarrollado un amplio potencial evolutivo para su adaptación que si bien les ha permitido aprovechar un recurso y ocupar ciertos nichos, también las hace ser muy vulnerables ante los cambios en su ambiente, de la cual son objeto a través de la colecta indiscriminada; destrucción, modificación y fragmentación de su hábitat, estas características provocan bajas tasas de crecimiento, ciclos de vida relativamente largos y escaso reclutamiento de nuevos individuos en condiciones naturales así como el establecimiento de asociaciones con polinizadores, micorrizas y con otros organismos que son a veces tan específicas y complejas. (IUCN/SSC 1996; Ospina 1996).

Dentro de estas asociaciones poco conocidas, pero no por eso menos importantes son las que han establecido las orquídeas con bacterias, estas se han encontrado dentro del sustrato donde se desarrollan y en las raíces de orquídeas tanto epífitas como terrestres. De los géneros bacterianos aislados de estas orquídeas, se ha demostrado que Azotobacter y la bacteria Bacillus radicicola promueven la germinación de semillas de orquídeas por la producción de la fitohormona auxina (IAA). Y bacterias de los géneros Pseudomonas, Bacillus, Arthrobacter, y Xanthomonas) y Sphingomonas sp, Microbacterium sp., Mycobacterium sp., Bacillus sp., Rhizobium sp., Rhodococcus sp., Cellulomonas sp., Pseudomonas sp., y Micrococcus luteus también tienen la capacidad de producir esta hormona. (Knudson, 1922; Wilkinson et al. 1989 y 1994; Tsavkelova et al. 2004a, 2004 b).

Por otra parte se tiene conocimiento del empleo de biofertilizantes en plantas de importancia agrícola como maíz, trigo, caña de azúcar, arroz, café y tomate entre otros, donde se han observado cambios importantes al aplicarse estos, en el proceso de germinación, desarrollo y producción de los cultivos, los biofertilizantes son producidos por diferentes géneros bacterianos: Azospirillum, Acetobacter, Azotobacter, Bacillus, Klebsiella, Rhizobium, Pseudomonas y Serratia, estas respuestas se deben a que los microorganismos aumentan el reciclado y la solubilización de los nutrientes minerales y sintetizan vitaminas, aminoácidos, auxinas, giberelinas, citoquininas y etileno; así como algunas de ellas fijan nitrógeno reduciendo de manera importante el uso de fertilizantes químicos cuyo uso a largo plazo tienen efectos negativos para el ambiente (Frankenberger \& Arshad 1995, Fuentes et al. 2003, Jiménez Salgado et al. 2004).

Aunque la composición de la microbiota asociada a orquídeas es de limitada especificidad, es importante realizar estudios sobre las poblaciones bacterianas que se encuentren asociadas a orquídeas en ambientes silvestres, ya que esta varía en función de las condiciones ambientales y del nicho ecológico en que se encuentren, además de las características morfológicas y fisiológicas que presentan las plantas y permitan el establecimiento de tales asociaciones. (Wilkinson et al. 1994).

En este trabajo se planteó estudiar la población de bacterias que se encuentran asociadas a dos especies de orquídeas Laelia furfuracea, especie endémica del estado de Oaxaca que crece en bosques de pino-encino, en clima frío seco y Oncidium sphacelatum especie tropical de amplia distribución. 
TABLA 1.Géneros bacterianos aislados de plantas de Laelia furfuracea.

\begin{tabular}{l|c|c|c|c|c|c} 
& Rizósfera & Rizoplano & Endófito Raíz & $\begin{array}{c}\text { Endófito } \\
\text { Hoja }\end{array}$ & $\begin{array}{c}\text { Endófito } \\
\text { Pseudobulbo }\end{array}$ & $\begin{array}{c}\text { Total } \\
\text { n=67 }\end{array}$ \\
\hline Azospirillum & $428.6 \%)$ & $4(28.6 \%)$ & $3(21.4 \%)$ & $2(14.3 \%)$ & $1(7.1 \%)$ & $14(20.9 \%)$ \\
\hline Enterobacter & $4(22.2)$ & $4(22.2)$ & $5(27.8)$ & $2(11.1)$ & $3(16.79$ & $18(26.9 \%)$ \\
\hline Pseudomonas & $3(25 \%)$ & $3(25 \%)$ & $3(25 \%)$ & $3(25 \%)$ & $3(25 \%)$ & $12(17.9 \%)$ \\
\hline Acetobactereas & $2(16.7 \%)$ & $3(25 \%)$ & $3(25 \%)$ & $1(8.3 \%)$ & $3(25 \%)$ & $12(17.9 \%)$ \\
\hline Herbaspirillum & $3(27.3 \%)$ & $2(18.2 \%)$ & $3(27.3 \%)$ & $2(18.2 \%)$ & $1(9.1 \%)$ & $11(16.4 \%)$ \\
\hline
\end{tabular}

TABLA 2.Géneros bacterianos aislados de plantas de Oncidium sphacelatum.

\begin{tabular}{l|c|c|c|c|c|c} 
& Rizósfera & Rizoplano & Endófito Raíz & $\begin{array}{c}\text { Endófito } \\
\text { Hoja }\end{array}$ & $\begin{array}{c}\text { Endófito } \\
\text { Pseudobulbo }\end{array}$ & $\begin{array}{c}\text { Total } \\
\text { n=81 }\end{array}$ \\
\hline Azospirillum & $4(20 \%)$ & $4(20 \%)$ & $4(20 \%)$ & $4(20 \%)$ & $4(20 \%)$ & $20(24.7 \%)$ \\
\hline Enterobacter & $3(21.4)$ & $4(28.6 \%)$ & $4(28.6)$ & $3(21.4 \%)$ & ND & $14(17.3 \%)$ \\
\hline Pseudomonas & $2(15.4 \%)$ & $4(30.8 \%)$ & $3(23.1 \%)$ & $3(23.1 \%)$ & $1(7.7 \%)$ & $13(16 \%)$ \\
\hline Acetobactereas & $4(22.2 \%)$ & $4(22.2 \%)$ & $4(22.2 \%)$ & $4(22.2 \%)$ & $2(11.1 \%)$ & $18(22.2 \%)$ \\
\hline Herbaspirillum & $3(18.8 \%)$ & $5(31.3 \%)$ & $5(31.3 \%)$ & $3(18.8 \%)$ & ND & $16(19.8 \%)$ \\
\hline
\end{tabular}

$\mathrm{ND}=$ No hubo aislamiento

\section{Material y Métodos}

La recolección de plantas de Laelia furfuracea se realizó en la parte noreste del estado Oaxaca en agosto del 2005 y de Oncidium sphacelatum en la sierra Nororiental del Estado de Puebla en marzo de 2006. Se recolectaron 4 plantas en cada uno de los sitios. El aislamiento de bacterias se hizo en las diferentes zonas anatómicas de las orquídeas: rizósfera, rizoplano y endófitos que corresponden a pseudobulbo (tallo), hoja y rizoma, lavados y desinfectados con una solución de Hipoclorito de Sodio al 1\% / 5 minutos, se enjuagó con agua destilada estéril (4 veces) y se maceró. Se procedió a inocular los viales con 100 $\mu 1$ de cada dilución en los medios: $\mathrm{Nfb}$, para aislar Azospirillum; $\mathrm{HNfb}$, para aislar Herbaspirillum; Mconkey en caldo e Hino y Wilson, para Klebsiella y bacterias entéricas; P4, para Pseudomonas; y LGI para Acetobacter se incubaron a $30^{\circ} \mathrm{C}$ durante 24-72 horas, transcurrido el tiempo de incubación se procedió a revisar el crecimiento característico en cada uno de los medios. En esta primera etapa se determinó la población bacteriana existente en las plantas de las orquídeas. Los viales positivos fueron resembrados en los mismos medios y se tomo la lectura de estos, posteriormente se tomo una asada y se sembraron por estría cruzada en los diferentes medios selec- tivos para cada uno de los géneros de bacterias: Azospirillum, Herbaspirillum, Klebsiella, Pseudomonas y Acetobacter.

\section{Resultados}

En las tablas 1, 2 y 3 se presentan las frecuencias y poblaciones de los géneros bacterianos aislados. En las muestras de orquídeas de Laelia furfuracea se encontraron 67 cepas bacterias de 5 géneros bacterianos. El género bacteriano con mayor frecuencia de aislamiento fue Enterobacter encontrándose en el interior de la raíz, seguido por Azospirillum en rizósfera y rizoplano, Pseudomonas en rizoplano $y$ Acetobacter fue menor en rizósfera e interior de la raíz, finalmente Herbaspirillum se encontró en un $16.4 \%$ siendo el menos frecuente y con mayor número de aislados en la zona de la rizósfera e interior de la raíz (tabla 1). En las plantas de Oncidium Sphacelatum se logró aislar un total de 81 cepas de bacterias, a diferencia de Laelia furfuracea el grupo con mayor frecuencia fue Azospirillum (24.7\%), seguido de las Acetobacter (22.2\%) presentó una frecuencia de aislamiento constante en las diferentes zonas a excepción de pseudobulbo; La mayor frecuencia de aislamiento de los géneros bacterianos correspondió a Pseudomonas con un (30.8\%) en la 
TABla 3. Población de microorganismos en $\log$ (células/ gramo de peso fresco) aislados de las diferentes plantas de orquídeas de Laelia furfuracea (Oaxaca) y Oncidium Sphacelatum (Puebla).

\begin{tabular}{l|c|c|c|c|c|c}
$\begin{array}{l}\text { Zona de } \\
\text { la planta }\end{array}$ & $\begin{array}{c}\text { Lugar } \\
\text { de muestreo }\end{array}$ & Azospirillum & Enterobacter & Pseudomonas & Acetobactereas & Herbaspirillum \\
\hline \multirow{2}{*}{ Rizósfera } & Oaxaca & 4.18 & 7.04 & 6.3 & 6.15 & 7.15 \\
\cline { 2 - 7 } & Puebla & 6.04 & 6.04 & 5.88 & 5.15 & 5.15 \\
\hline \multirow{2}{*}{ Rizoplano } & Oaxaca & 7.15 & 7.15 & 6.3 & 6.15 & 7.15 \\
\cline { 2 - 7 } & Puebla & 7.15 & 7.15 & 7.15 & 7.15 & 7.15 \\
\hline \multirow{2}{*}{ Endófito Raíz } & Oaxaca & 5.15 & 7.15 & 6.15 & 6.15 & 7.18 \\
\cline { 2 - 7 } & Puebla & 7.15 & 7.15 & 7.15 & 7.15 & 4.65 \\
\hline \multirow{2}{*}{$\begin{array}{l}\text { Endófito Hoja } \\
\text { Pseudobulbo }\end{array}$} & Oaxaca & 2.65 & 2.65 & 4.04 & 4.04 & 4.18 \\
\cline { 2 - 7 } & Puebla & 5.7 & 5.18 & 5.06 & 4.78 & 3.18 \\
\hline
\end{tabular}

$\mathrm{ND}=$ No hubo aislamiento

zona del rizoplano, se puede observar en la tabla 2 que la frecuencia en la zona de pseudobulbo fue baja y nula para algunos microorganismos como Enterobacter y Herbaspirillum.

En relación a las poblaciones (tabla 3) en Laelia furfuracea, las mayores poblaciones se encontraron en rizósfera y rizoplano, en cambio en Oncidium sphacelatum se encontraron en rizoplano e interior de la raíz. En Laelia furfuracea el género bacteriano con mayor población en rizósfera fue Herbaspirillum (7.15 log cel/gr de peso fresco) y en Oncidium sphacelatum fueron Azospirillum y Acetobacter (6.04 log cel/gr de peso fresco). En Oncidium sp. en rizoplano, las poblaciones fueron constantes y elevadas para los 5 géneros (7.15 $\log$ cel/gr de peso fresco) y en Laelia sp., Acetobacter y Pseudomonas tuvieron una menor población $(6.15 \mathrm{y}$ $6.3 \mathrm{log} \mathrm{cel} / \mathrm{gr}$ de peso fresco respectivamente).

En cuanto a microorganismos endófitos, se encontró que Enterobacter tuvo una mayor población en Laelia $s p$. en el interior de la raíz (7.15 log cel/gr) y en Oncidium sp. los 5 géneros presentaron las mismas poblaciones (7.15 log cel/gr). Al interior de la hoja las poblaciones disminuyeron en las dos especies de orquídeas, sin embargo en Laelia sp. el género más representativo fue Herbaspirillum (4.65 log cel/gr), y para Oncidium sp. fue Azospirillum (5.7 log cel/gr). En el interior de pseudobulbo las poblaciones de las bacterias disminuyen y no se detectan ni Azospirillum ni Enterobacter; Acetobacter y Pseudomonas presentan una población de $2.65 \mathrm{log}$ cel/gr y Herbaspirillum presenta la mayor población dentro de los géneros
(3.18 log cel/gr), para ambas especies de orquídeas (tabla 3).

Los datos anteriores son de los primeros informes sobre la asociación de Enterobacterias, Pseudomonas y microorganismos fijadores de nitrógeno (Azospirillum, Enterobacter y Herbaspirillum) en este tipo de cultivos como los que se tienen sobre la asociación de cultivos de tipo perenne como el café con Acetobacter diazotrophicus (Jiménez y col.,19979 y Azospirillum (Jiménez,Salgado y col 2004)..En contraste existen numerosos reportes sobre la asociación benéfica de enterobacterias, azospirilla y pseudomonas con cultivos económicamente importantes y de ciclo corto como maíz, trigo, caña de azúcar y arroz entre otros (Okon y Labandera-González, 1994; Haahtela y col, 1988; Barraquio, 1983).

La rizósfera ha sido el lugar donde se han encontrado la mayoría de los microorganismos que han resultado benéficos para los cultivos (Sundaram y col., 1988), aunque también es ahí donde habitan bacterias que pueden ocasionar daño a la planta hospedera. Los microorganismos se encuentran localizados sobre la capa mucilaginosa de la superficie de la raíz y en los tejidos superficiales de la misma, de donde reciben carbono orgánico en forma de exudados, secreciones y tejidos muertos. La presencia de bacterias en las otras zonas anatómicas de las orquídeas indica que existe un mecanismo por el cual pueden llegar al interior, así como su capacidad para poder adaptarse a las nuevas condiciones imperantes a su alrededor. La situación actual de la bacteria y su abundancia dentro 
de la raíz no se conoce perfectamente pero su capacidad de sobrevivir en el interior de las plantas con poca o ninguna competencia las hace candidatos potenciales para el control biológico (Misagui \& Donndelinger 1990).

\section{LITERATURA CITADA}

Barraquio W.L., J.K. Ladha \& I. Watanabe. 1983. Isolation and identification of $\mathrm{N}_{2}$-fixing Pseudomonas associated with wetland rice. Can. J. Microbiol. 29 : 867-873.

Frankenberger W.T. \& M. Arshad. 1995. Phytohormones in soils; microbial production and Function. Marcel Dekker, New York

Fuentes R.L.E., H.A. Tapia, S.T. Jiménez, E.M.A. Mascarúa, P.Y. Santoyo, V.L.R. Caso, H.H.T. Romero, E.M. del R. Cajica, B.D. León, P.M. Rosales, M.P. Füguemann \& R.M.G. Castillo. 2003. Bacterias acéticas: diversidad e interacción con las plantas, Elementos 49(10): 47.

Haahtela K., T. Laakso, E.L. Nurmiaho \& T. Korhonen. 1988. Effects of inoculation of Poa pratensis and Triticum aestivum with root-associated, N2-fixing Klebsiella, Enterobacter and Azospirillum. Plant and Soil. 106: 239-247.

IUCN/SSC Orchid Specialist Group. 1996. Orchids Status survey and conservation action plan. IUCN, Gland Switzerland and Cambridge, UK.

Jiménez S.L., C.H. Vázquez \& H.A. Tapia. 2001. Response of the coffee plant to the inoculation with Azospirillum sp. In: Nitrogen fixation: global perpectives. Proceedings of the $13^{\text {th }}$ International Congress on nitrogen fixation.Hamilton, Ontario, Canada.

Jiménez Salgado T., L.E. Fuentes-Ramírez, L.E., A. TapiaHernández, E.M.A. Mascarúa-Esparza, E. MartínezRomero \& J. Caballero Mellado. 1997. Coffea arabica
L., new host plant for Acetobacter diazotrophicus and isolation of other nitrogen fixing acetobacteria. Appl. Environ. Microbiol. 63(9): 3676-3683.

Knudson, L., 1922. Nonsymbiotic Germination of Orchid Seeds, Bot. Gaz. 73(1): 1-25.

Misaghi I.J. \& C.R. Donndelinger. 1990. Endophytic bacteria in symptom-free cotton plants. Phytopathology 80 : 808-811.

Okon Y. \& C.R. Labandera-González. 1994. Agronomic applications of Azospirillum: an evaluation of 20 years worldwide field inoculation. Soil. Biol. Biochem. 26: 1591-1601.

Ospina, H. M., 1996, Orchidology and Biotechnology, Orchids: 1072-1074.

Red de ornamentales 2004. (http://www.uaemex.mx/ornamentalesred/home.html)

Soto-Arenas, M. A. 1996. México (Regional account). Pp. 53-58 in: IUCN/SSC Orchid Specialist Group. Orchids. Status survey and conservation action plan, UICN.

Sundaram S., A. Araunakumari \& R. Klucas. 1988. Characterization of Azospirilla isolated from seeds and roots of turf grass. Can. J. Microbiol. 34 : 212-217.

Tsavkelova, E.A., T.A. Cherdyntseva \& A.I. Netrusov. 2004a. Bacteria associated with roots of epiphytic orchids. Mikrobiologiya 73(6): 825-831.

Tsavkelova, E.A., T.A. Cherdyntseva \& A.I. Netrusov. $2004 \mathrm{~b}$. Auxin production by bacteria associated with orchid roots. Microbiology 74(1): 46-53, translated from Mikrobiologiya 74(1): 55-62.

Wilkinson K. H., K.W. Dixon \& K. Sivasithamparam. 1989. Interaction of soil bacteria, mycorrhizal fungi and orchid seed in relation to germination of Australian orchids. New Phytol., 112: 429-435

Wilkinson, K.G., K.W. Dixon, K. Sivasithamparam \& E.L. Ghisalberti. 1994. Effect of IAA on symbiotic germination of an Australian orchid and its production by orchid-associated bacteria. Plant Soil 159: 291-295.

Emilia Ramos Zambrano es estudiante de la Escuela de Biología de la Benemérita Universidad Autónoma (BUAP) de México, y actualmente realiza un estudio de bacterias asociadas a orquídeas benéficas para su crecimiento en el laboratorio de Microbiología del suelo ICUAP. Se interesa en la reproducción de orquídeas para un aprovechamiento sustentable.

Teresita Jiménez Salgado es profesora investigadora en Microbiología del suelo en el Instituto de Ciencias de la BUAP. Sus intereses son la biofertilización en cultivos de interés agrícola y la biotecnología agrícola. Ha realizado estudios de la diversidad de microorganismos asociados al cultivo del café y orquídeas en México.

Armando Tapia Hernández es profesor investigador en Microbiología del suelo en el Instituto de Ciencias (ICBUAP). Sus principales líneas de investigación son la biofertilización (donde ha realizado estudios de microorganismos asociados a orquídeas) y la biotecnología agrícola, con énfasis en la biorremediación de suelos contaminados con hidrocarburos. 